\title{
AVALIAÇÃO DE MUDAS DA ALFACE CV. ELBA (Lactuca sativa L.) EM DIFERENTES SUBSTRATOS
}

\author{
Edvan Costa da Silva ${ }^{1}$, Adynna Nayara Silva Marques ${ }^{2}$, Léo Vieira Leonel ${ }^{3}$ \\ ${ }^{1}$ Mestrando em Produção Vegetal, Universidade Estadual do Goiás - UEG, Campus Ipameri - GO. \\ Email:edvan_costa@outlook.com \\ ${ }^{2}$ Engenheira Agrônoma, Universidade Estadual do Maranhão - UEMA, Campus Imperatriz - MA. \\ ${ }^{3}$ Mestre em Agroecologia, Universidade Estadual do Maranhão - UEMA, Campus São Luís - MA.
}

RESUMO: O substrato utilizado na produção de alface (Lactuca sativa L.), exerce papel primordial, no desenvolvimento inicial da planta. Neste sentido, com o presente trabalho objetivou-se avaliar a produção de mudas de alface em função de diferentes combinações de substratos. $\mathrm{O}$ experimento foi implantado em um delineamento inteiramente casualizado, com seis repetições. Constituídas por 24 mudas cada. Utilizou-se a variedade de alface Elba. Determinou-se o número de folhas (NF) em unidades de cada planta; comprimento de parte aérea (CPA) em cm; comprimento da raiz (CR) em $\mathrm{cm}$; massa fresca da parte aérea (MFPA) e a massa fresca da raiz (MFRA) foram pesadas em balança analítica com precisão de $0,001 \mathrm{~g}$ e os resultados obtidos registrados em g. planta $^{-1}$. Foram avaliados quatro substratos, sendo um a própria terra, e três alternativos que foram escolhidos devido a sua disponibilidade na região: cama de frango, palha de arroz carbonizada, esterco de gado. Para todas as avaliações, ao final do ciclo da alface, de todos os outros substratos orgânico o que teve um maior valor significativo para desenvolvimento da cultura, foi o que continha terra preta + cama de frango.

Palavras-chave:Alface. Substrato. Cama-de-frango. Esterco. Palha de arroz.

\section{EVALUATION OF LETTUCE CHANGES CV. ELBA (Lactuca sativa L.) IN DIFFERENT SUBSTRATES}

\begin{abstract}
The substrate used in the production of lettuce (Lactuca sativa L.) plays major role in the initial development of the plant. In this sense, the present work aimed to evaluate the production of lettuce seedlings depending on substrates of different combinations. The experiment was carried out following a completely randomized design with six replications. Consisting of 24 seedlings each. We used a variety of Elba lettuce. It was determined the number of sheets (NF) in each plant units; shoot length (CPA) in $\mathrm{cm}$; root length (CR) in $\mathrm{cm}$; fresh weight of shoot (MFPA) and the fresh weight of the root (MFRA) were weighed in an analytical balance with an accuracy of $0.001 \mathrm{~g}$, and the results recorded in g. plant ${ }^{-1}$.Were evaluated four substrates, one being the land itself, and three alternatives that were chosen due to their availability in the region: chicken manure, carbonized rice husks, livestock manure. For all evaluations at the end of lettuce cycle, all
\end{abstract}

Cultura Agronômica, Ilha Solteira,v.26, n.4, p.520-529, 2017 
other organic substrates which had a most significant value to the development of culture, was what it contained black soil + poultry litter.

Key words:Lettuce. Substrate. Bed-of-chicken manure. Rice straw.

\section{INTRODUÇÃO}

Originária da Ásia e trazida pelos portugueses no século XVI, a alface (Lactuca sativa L.) é a mais popular das hortaliças folhosas e é cultivada em quase todas as regiões do globo terrestre (RESENDE et al., 2003). No Brasil, a alface é a sexta hortaliça em importância econômica e a oitava em volume de produção (NADAL et al, 1986), sendo cultivada em todas as regiões do país. A alface é considerada a hortaliça folhosa mais importante na alimentação dos brasileiros, o que assegura à cultura expressiva importância econômica.

A produção agrícola é altamente dependente da produção de insumos e, nesse contexto, os substratos têm se destacado devido à sua ampla utilização na produção de mudas de hortaliças (SILVEIRA et al., 2002). A prática de uso de substratos na produção agrícola data de 1941, na Califórnia (BOOMAN, 2000). No entanto, a difusão de pesquisas na área ocorreu mais tarde, a partir do International Workgroup onSoilessCulture de 1955, como descreve Kämpf (2006). Substrato é descrito como sendo um produto usado como meio de crescimento de plantas e que como tal deve seguir determinadas exigências.

A qualidade de um substrato para o abastecimento de bandejas depende de sua estrutura física e composição química e de sua qualidade dependem as plantas produzidas (MIRANDA et al., 1998), sendo que sua principal função prover suporte às plantas nele cultivadas (RÖBER, 2000). Atualmente, a maioria dos substratos é uma mistura de dois ou mais componentes, realizada para que as propriedades químicas e físicas se tornem adequadas às necessidades específicas de cada cultivo (FONTENO,1993). A turfa, material orgânico originário de áreas úmidas é o componente mais usado nos Estados Unidos, Canadá e por grande parte da Comunidade Européia (BOOMAN, 2000) e atualmente, ainda no Brasil. Com o fechamento de muitas turfeiras, a fibra de coco, com estrutura física de uniformidade bastante adequada, surgiu como uma boa alternativa para a substituição das turfas e deve promover grandes mudanças na qualidade dos substratos (BOOMAN, 2000).

No Brasil, existem ainda muitas controvérsias e dúvidas quanto aos métodos que devam ser usados para caracterizar substratos, no entanto com a definição da metodologia específica para substratos (ABREU, 2006), que deverá, provavelmente, estabelecer, a mesma metodologia definida em 2003, pelo Comitê de Normatização Européia, será possível comparar os valores obtidos aos recomendados.

Para Gruszynski (2002), os aspectos principais nas propriedades físicas de um substrato são as propriedades das partículas que compõem a fração sólida (forma e tamanho), superfície específica e característica de interação com a água (molhabilidade) e a geometria do espaço poroso formado entre essas partículas, dependente das propriedades 
das partículas e da forma como o material é manuseado, principalmente da densidade de enchimento no recipiente, que determina a porosidade total e o tamanho dos poros. A capacidade de troca de cátions (CTC), o pH, o teor de matéria orgânica e a salinidade são as propriedades químicas mais importantes dos substratos sendo que a nutrição das plantas é de responsabilidade do produtor (SCHMITZ et al., 2002). A faixa de pH ideal para um substrato varia muito de acordo com a espécie a ser cultivada, porém pode-se considerar como de 5,5 a 6,5, onde ocorre a disponibilidade da maioria dos nutrientes (BAUMGARTEN, 2002).

A capacidade de troca de cátions, segundo Gruszynski (2002), está diretamente relacionada com o nível tecnológico (manejo de fertirrigação) do produtor de mudas, capaz de controlar a ampla reserva dos nutrientes. A condutividade elétrica, indicativo da concentração de sais devem se situar entre 0,8 e $1,5 \mathrm{dS} \mathrm{m}^{-1}$ (obtidos pela extração em água na proporção de 1 parte de substrato para 1,5 partes de água destilada), segundo Baumgarten (2002). Schmitzet al., (2002) assumindo que 50 a $60 \%$ da matéria orgânica é constituída por carbono, estabeleceram que os teores ideais de carbono orgânico para substratos usados em recipientes, com fornecimento esporádico de água e nutrientes, devem ficar acima de $25 \%$.

O uso dos substratos possibilitou aos produtores uma série de vantagens, como a racionalização de mão-de-obra, de insumos e de fertilizantes, garantindo a formação de mudas com melhor arquitetura, por outro lado a grande variabilidade de substratos e preços existentes no mercado, associados à falta de uniformidade química e física entre os lotes de fabricação, pode comprometer o planejamento da atividade, já que o transplante das mudas pode ocorrer com atrasos que acarretam custos adicionais ao produtor e em ônus maior para o consumidor. Para Luz et al. (2000) a modernização da agricultura e a segmentação do mercado, trouxeram a especulação na atividade de produção de mudas; os substratos comerciais de boa qualidade possuem custo elevado.

Neste sentido, com o presente trabalho objetivou-se avaliar a produção de mudas de alface em função de diferentes combinações de substratos.

\section{MATERIAL E MÉTODOS}

O experimento foi conduzido em uma casa de vegetação localizada no Centro de Desenvolvimento Tecnológico (Infraero) em Imperatriz - MA, nos meses de fevereiro a março do ano de 2014. Foi escolhido a cultivar Elba, por sua boa aceitação pelos produtores e consumidores da região.

Foi utilizado um delineamento inteiramente casualizado (DIC), com quatro tratamentos e 6 repetições, constituídas por 24 mudas cada. Utilizou-se a variedade de alface Elba. Foram avaliados quatro substratos na produção de mudas de alface, sendo um a própria terra (Tabela 1), e três alternativos que foram escolhidos devido a sua disponibilidade na região: cama de frango, palha de arroz carbonizada, esterco de gado (Tabela 1).

Cultura Agronômica, Ilha Solteira,v.26, n.4, p.520-529, 2017 
Foi realizada a semeadura das sementes no mês de fevereiro do ano de 2014, em bandejas de polietileno de 128 células, onde foram distribuídas quatro sementes por parcela, após a emergência das plântulas, foi feito um desbaste, permanecendo uma planta por célula. Durante a condução do experimento, as plântulas foram irrigadas diariamente, mantendo a umidade dos substratos próxima à capacidade de campo.

Tabela 1. Composição química do solo e dos substratos testados para produção de mudas de alface cv. Elba (Lactuca sativa L.).

\begin{tabular}{|c|c|c|c|c|}
\hline \multicolumn{5}{|c|}{ ANÁLISE QUÍMICA } \\
\hline Itens Analisados & Solo (terra preta) & $\begin{array}{l}\text { Esterco } \\
\text { Bovino }\end{array}$ & $\begin{array}{c}\text { Palha de } \\
\text { Arroz } \\
\text { Carbonizada }\end{array}$ & Cama de Frango \\
\hline M.O. & $10,9\left(\mathrm{~g} / \mathrm{dm}^{3}\right)$ & $18\left(\mathrm{~g} \mathrm{~kg}^{-1}\right)$ & $280\left(\mathrm{~g} \mathrm{~kg}^{-1}\right)$ & $430\left(\mathrm{~g} \mathrm{~kg}^{-1}\right)$ \\
\hline $\mathrm{C} / \mathrm{N}\left(\mathrm{g} \mathrm{kg}^{-1}\right)$ & - & $18 / 1$ & $37 / 1$ & $16 / 1$ \\
\hline $\mathbf{N}\left(\mathbf{g ~ k g}^{-1}\right)$ & - & 13 & 4,6 & 40 \\
\hline $\mathbf{P H}\left(\mathrm{CaCl}_{2}\right)$ & 4,7 & 6,7 & 6,3 & 7,8 \\
\hline $\mathbf{P}$ & $19,6\left(\mathrm{mg} / \mathrm{dm}^{3}\right)$ & $1,5\left(\mathrm{~g} \mathrm{~kg}^{-1}\right)$ & $2,2\left(\mathrm{~g} \mathrm{~kg}^{-1}\right)$ & $38\left(\mathrm{~g} \mathrm{~kg}^{-1}\right)$ \\
\hline $\mathbf{K}$ & $5,1\left(\mathrm{mmolc} / \mathrm{dm}^{3}\right)$ & $2,4\left(\mathrm{~g} \mathrm{~kg}^{-1}\right)$ & $6,2\left(\mathrm{~g} \mathrm{~kg}^{-1}\right)$ & $32\left(\mathrm{~g} \mathrm{~kg}^{-1}\right)$ \\
\hline $\mathbf{C a}$ & $28,2\left(\mathrm{mmolc} / \mathrm{dm}^{3}\right)$ & $\begin{array}{c}11,3\left(\mathrm{~g} \mathrm{~kg}^{-}\right. \\
1)\end{array}$ & $21,5\left(\mathrm{~g} \mathrm{~kg}^{-1}\right)$ & $62\left(\mathrm{~g} \mathrm{~kg}^{-1}\right)$ \\
\hline Mg & 15,2 (mmolc/dm $\left.{ }^{3}\right)$ & $2,8\left(\mathrm{~g} \mathrm{~kg}^{-1}\right)$ & $2,1\left(\mathrm{~g} \mathrm{~kg}^{-1}\right)$ & $8\left(\mathrm{~g} \mathrm{~kg}^{-1}\right)$ \\
\hline $\mathbf{N a}$ & $8\left(\mathrm{mmolc} / \mathrm{dm}^{3}\right)$ & $0,4\left(\mathrm{~g} \mathrm{~kg}^{-1}\right)$ & $5,8\left(\mathrm{~g} \mathrm{~kg}^{-1}\right)$ & - \\
\hline SB (mmolc/dm $\left.{ }^{3}\right)$ & 56,6 & - & - & - \\
\hline Al (mmolc/dm³ $\left.{ }^{3}\right)$ & 4,3 & - & - & - \\
\hline H (mmolc/dm $\left.{ }^{3}\right)$ & 42,8 & - & - & - \\
\hline CTC (mmolc/dm $\left.{ }^{3}\right)$ & 103,7 & - & - & - \\
\hline $\mathrm{Na} / \mathrm{CTC}(\%)$ & 9 & - & - & - \\
\hline Al/Al+SB (\%) & 9,2 & - & - & - \\
\hline $\mathrm{V}(\%)$ & 63,3 & - & - & - \\
\hline
\end{tabular}

As mudas foram retiradas das bandejas quando estavam aptas para o transplante no canteiro definitivo. Foram semeadas no canteiro em ambiente protegido, as avaliações dos caracteres das mudas foram feitas sempre no período da manhã, entre os meses de fevereiro e março de 2014. As avaliações foram procedidas aos 15, 30 e 45 dias, onde foram lavadas em água para remoção do substrato das raízes, e em seguida cortadas no colo a fim de separar a parte aérea do sistema radicular.

Determinou-se o número de folhas (NF) em unidades de cada planta; comprimento de parte aérea (CPA) em cm; comprimento da raiz $(\mathrm{CR}) \mathrm{em} \mathrm{cm}$; massa fresca da parte aérea (MFPA) e a massa fresca da raiz (MFRA) foram pesadas em balança analítica com precisão de $0,001 \mathrm{~g}$ e os resultados obtidos registrados em g. planta $^{-1}$.

As análises de variância do ensaio disposto foram realizadas seguindo as recomendações de Ferreira (2000) e, as médias dos caracteres avaliados em substratos alternativos para a produção de mudas de alface foram comparadas pelo teste de Tukey, a 5\% de probabilidade, utilizando-se o aplicativo computacional ASSISTAT 7.6.

Cultura Agronômica, Ilha Solteira,v.26, n.4, p.520-529, 2017 


\section{RESULTADOS E DISCUSSÃO}

De acordo com as análises realizadas, para os parâmetros avaliados (número de folhas, peso da parte aérea, peso da raiz, comprimento da parte aérea e comprimento da raiz), o número de folhas apresentou diferença significativa a $1 \%$ de probabilidade quando tratado com substrato composto de terra preta (Tabela 1) analisada aos 15 dias após o plantio (Tabela 2). Segundo Pio et al. (2004) a mistura terra:areia:esterco na proporção 2:1:1, promoveu médias com maior número de folhas e massa fresca das brotações em comparação aos demais substratos e misturas em estudo pelo autor.

Tabela 2. Avaliação dos componentes de promoções do crescimento de plantas (numero de folhas, peso da parte aérea, peso da raiz, comprimento da parte aérea e comprimento da raiz) de Lactuta sativa (L.) mediadas por diferentes substratos aos 15 dias de semeadura.

\begin{tabular}{lccccc}
\hline \multirow{2}{*}{ Tratamentos } & \multicolumn{5}{c}{ Componentes de promoção de crescimento } \\
\cline { 2 - 6 } & $\begin{array}{c}\mathbf{N}^{\mathbf{0}} \mathbf{d e} \\
\text { folhas }\end{array}$ & $\begin{array}{c}\text { Peso da parte } \\
\text { aérea }(\mathbf{g})\end{array}$ & $\begin{array}{c}\text { Peso da } \\
\text { raiz }(\mathbf{g})\end{array}$ & $\begin{array}{c}\text { Comp. da parte } \\
\text { aérea }(\mathbf{c m})\end{array}$ & $\begin{array}{c}\text { Comp. da } \\
\text { raiz }(\mathbf{c m})\end{array}$ \\
\hline T0 - Terra preta & $7,0 \mathrm{a}$ & $3,6 \mathrm{a}$ & $0,8 \mathrm{a}$ & $16,7 \mathrm{a}$ & $6,5 \mathrm{a}$ \\
T1 - Esterco de gado & $5,0 \mathrm{ab}$ & $2,1 \mathrm{a}$ & $1,2 \mathrm{a}$ & $10,2 \mathrm{~b}$ & $5,9 \mathrm{ab}$ \\
T2 - Cama de frango & $4,2 \mathrm{~b}$ & $2,1 \mathrm{a}$ & $0,6 \mathrm{a}$ & $13,2 \mathrm{ab}$ & $5,9 \mathrm{ab}$ \\
T3 - Palha de arroz & $6,2 \mathrm{ab}$ & $3,4 \mathrm{a}$ & $0,5 \mathrm{a}$ & $13,0 \mathrm{ab}$ & $4,5 \mathrm{~b}$ \\
carbonizada & & & & & \\
\hline \multicolumn{1}{c}{ CV (\%) } & 23,24 & 44,91 & 71,08 & 25,10 & 19,21 \\
\hline \multicolumn{1}{c}{$\mathbf{F}$} & $5,58^{* *}$ & $2,34^{\mathrm{ns}}$ & $1,73^{\mathrm{ns}}$ & $3,73^{*}$ & $3,58^{*}$ \\
\hline
\end{tabular}

ns_- Não significativo; ${ }^{*}$ - significativo a $5 \%$ de probabilidade; ${ }^{* *}$ - significativo a $1 \%$ de probabilidade. As médias seguidas pela mesma letra não diferem estatisticamente entre si. Foi aplicado o Teste de Tukey ao nível de $5 \%$ de probabilidade.

As variáveis de componentes de crescimento de plantas massa fresca da parte aérea e massa fresca da raiz (g), não apresentaram efeitos significativos ao nível de $5 \%$ de probabilidade, mostrando que os tratamentos apresentados não forneceram subsídios essenciais para o desenvolvimento destes componentes. A interação dos tratamentos com as variáveis apresentaram coeficientes de rendimento relativamente altos, apresentando assim efeito negativo para avalição destas variáveis aos 15 dias de semeadura.

$\mathrm{Na}$ avaliação do comprimento da parte aérea e do comprimento da raiz, houve variação significativa dos tratamentos, apontando a terra preta como o substrato que apresentou desenvolvimento satisfatório destas componentes aos 15 dias de semeadura (Tabela 2). Alves (2011) avaliando a qualidade de diferentes substratos alternativos observou que o esterco bovino + húmus de minhoca e esterco bovino + esterco de galinha proporcionaram melhor produção de mudas de alface, em relação às variáveis: altura de plantas, índice de velocidade de emergência, peso seco e emergência de plântulas.

Com relação ao número de folhas avaliadas aos 30 dias de semeadura, não houve efeito significativo entre nenhum dos tratamentos aplicados, não havendo interação entre os substratos utilizados (Tabela 3). Para a avaliação do peso da parte aérea, o tratamento 
utilizando substrato cama de frango apresentou efeito positivo para essa variável. O substrato deve apresentar características físicas, químicas e biológicas apropriadas para que permita pleno crescimento das raízes e da parte aérea (SETUBAL; AFONSO NETO, 2000). Hartmannet al. (1990) mencionam que os principais efeitos dos substratos se manifestam sobre as raízes podendo influenciar o crescimento da parte aérea.

As componentes de crescimento de plantas peso da raiz, comprimento da parte aérea e comprimento da raiz não apresentaram efeitos significativos. Para o peso da raiz os tratamentos utilizados não apresentaram efeito interativo entre os substratos, mostrando que para 30 dias de transplantio o peso da raiz não apresenta valor significativo (Tabela 3).

Para as componentes comprimento da parte aérea e comprimento da raiz a não houve diferença entre os substratos utilizados, porém, avaliação apresenta pelo teste que os tratamentos utilizados e a metodologia apresentada para avalição apresentou-se significativa. Contudo, os tratamentos avaliados mostraram-se indiferentes para avalição dos dois parâmetros (comprimento da parte aérea e comprimento da raiz), analisando-se que os tratamentos não apresentaram efeito significativo para as variáveis avaliadas aos 30 dias (Tabela 3).

Tabela 3. Avaliação dos componentes de promoções do crescimento de plantas (numero de folhas, peso da parte aérea, peso da raiz, comprimento da parte aérea e comprimento da raiz) de Lactuta sativa (L.) mediadas por diferentes substratos aos 30 dias de semeadura.

\begin{tabular}{|c|c|c|c|c|c|}
\hline \multirow[b]{2}{*}{ Tratamentos } & \multicolumn{5}{|c|}{ Componentes de promoção de crescimento } \\
\hline & $\begin{array}{l}N^{\circ} \text { de } \\
\text { folhas }\end{array}$ & $\begin{array}{l}\text { Peso da parte } \\
\text { aérea }(\mathrm{g})\end{array}$ & $\begin{array}{l}\text { Peso da } \\
\text { raiz (g) }\end{array}$ & $\begin{array}{l}\text { Comp. da parte } \\
\text { aérea }(\mathrm{cm})\end{array}$ & $\begin{array}{l}\text { Comp. da } \\
\text { raiz }(\mathrm{cm})\end{array}$ \\
\hline T0 - Terra preta & $6,5 \mathrm{a}$ & $7,7 \mathrm{ab}$ & $0,8 \mathrm{a}$ & $26,2 \mathrm{a}$ & $8,1 \mathrm{a}$ \\
\hline T1 - Esterco de gado & $7,0 \mathrm{a}$ & $6,6 \mathrm{~b}$ & $1,1 \mathrm{a}$ & $21,3 \mathrm{a}$ & $10,2 \mathrm{a}$ \\
\hline T2 - Cama de frango & $8,5 \mathrm{a}$ & $12,5 \mathrm{a}$ & $1,4 \mathrm{a}$ & $20,9 \mathrm{a}$ & $10,7 \mathrm{a}$ \\
\hline $\begin{array}{l}\text { T3 - Palha de arroz } \\
\text { carbonizada }\end{array}$ & $7,1 \mathrm{a}$ & $6,0 \mathrm{~b}$ & $1,0 \mathrm{a}$ & $24,2 \mathrm{a}$ & $8,1 \mathrm{a}$ \\
\hline $\mathrm{CV}(\%)$ & 29,39 & 40,23 & 54,67 & 14,77 & 19,43 \\
\hline $\mathbf{F}$ & $0,95^{\mathrm{ns}}$ & $4,78^{*}$ & $1,07^{\mathrm{ns}}$ & $3,23^{*}$ & $3,66^{*}$ \\
\hline
\end{tabular}

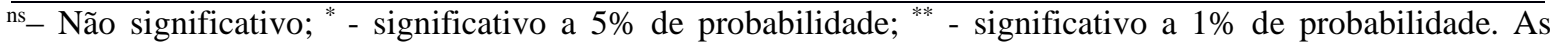
médias seguidas pela mesma letra não diferem estatisticamente entre si. Foi aplicado o Teste de Tukey ao nível de $5 \%$ de probabilidade.

Resultados encontrados por Carneiro (2010) demonstram que o uso de composto por solo esterilizado, vermiculita fina, esterco bovino na proporção (2:1:1), e o uso de outros substratos orgânicos alternativos como cama de frango e palha de arroz carbonizada, pode ser utilizado por produtores de mudas de alface, uma vez que gera muda de alta qualidade e bom rendimento no campo ao serem transplantadas. Ainda neste, afirma-se que as bandejas contendo 200 células são melhores, haja vista que estas proporcionam um bom rendimento das mudas e dos substratos.

Em trabalhos com tomateiro a adição de substratos orgânicos alternativos foi favorável ao acúmulo de matéria seca na parte aérea de plântulas de tomate (DINIZ et al., Cultura Agronômica, Ilha Solteira,v.26, n.4, p.520-529, 2017 
2006). Esses resultados expressam uma característica importante pois o reinício do desenvolvimento da planta após o processo de transplante, é favorecido por tecidos ricos em massa seca (FILGUEIRA, 2003).

Para a avaliação dos parâmetros aos 45 dias de transplantio, em todas as variáveis houve diferença significativa. Na análise do número de folhas, peso da parte aérea e da raiz, comprimento da raiz, o substrato cama de frango apresentou desempenho favorável para promoção de crescimento de alface (Tabela 4).

Ayusoet al. (1996) explicam que a resposta para a parte aérea é dependente de mais variáveis, como a espécie vegetal, a variedade da planta, a matéria-prima utilizada para extrair nutrientes e a sua origem. Com relação ao crescimento das raízes, Silva et al. (2011) consideram como um dos principais efeitos fisiológicos das substâncias húmicas em plantas em contrapartida o uso de substratos orgânicos favorecem o desenvolvimento da parte aérea e da raiz.

Influência no desenvolvimento da parte aérea de plantas também foi observada por Baldottoet al. (2009), estudando o efeito de substâncias húmicas quando avaliada em substrato orgânico de origem animal no desenvolvimento de abacaxizeiro, onde a aplicação de $\mathrm{AH}$ extraídos das fontes vermicomposto e torta de filtro, proporcionou incrementos de 51,$53 ; 10,12$ e $59,13 \%$ na área foliar, número de folhas e matéria seca foliar, respectivamente.

Tabela 4. Avaliação dos componentes de promoções do crescimento de plantas (numero de folhas, peso da parte aérea, peso da raiz, comprimento da parte aérea e comprimento da raiz) de Lactuta sativa (L.) mediadas por diferentes substratos aos 45 dias de semeadura.

\begin{tabular}{|c|c|c|c|c|c|}
\hline \multirow[b]{2}{*}{ Tratamentos } & \multicolumn{5}{|c|}{ Componentes de promoção de crescimento } \\
\hline & $\begin{array}{l}N^{\circ} \text { de } \\
\text { folhas }\end{array}$ & $\begin{array}{c}\text { Peso da parte } \\
\text { aérea (g) }\end{array}$ & $\begin{array}{l}\text { Peso da } \\
\text { raiz (g) }\end{array}$ & $\begin{array}{l}\text { Comp. da parte } \\
\text { aérea }(\mathrm{cm})\end{array}$ & $\begin{array}{l}\text { Comp. da } \\
\text { raiz }(\mathrm{cm})\end{array}$ \\
\hline T0 - Terra preta & 7,3 b & $10,8 \mathrm{~b}$ & $1,5 \mathrm{~b}$ & $26,5 \mathrm{ab}$ & $9,5 \mathrm{~b}$ \\
\hline T1 - Esterco de gado & $13,7 \mathrm{~b}$ & $15,1 \mathrm{~b}$ & $5,3 \mathrm{ab}$ & $31,7 \mathrm{a}$ & $9,8 \mathrm{~b}$ \\
\hline T2 - Cama de frango & $26,8 \mathrm{a}$ & 39,0 a & $7,9 \mathrm{a}$ & $29,8 \mathrm{ab}$ & $14,3 \mathrm{a}$ \\
\hline $\begin{array}{l}\text { T3 - Palha de arroz } \\
\text { carbonizada }\end{array}$ & $8,8 \mathrm{~b}$ & $9,1 \quad b$ & $0,9 \mathrm{~b}$ & $23,2 \mathrm{~b}$ & $12,5 \mathrm{ab}$ \\
\hline $\mathrm{CV}(\%)$ & 34,74 & 57,20 & 79,33 & 14,74 & 13,63 \\
\hline $\mathbf{F}$ & $19,48 * *$ & $10,33 * *$ & $6,78 * *$ & $4,95 * *$ & $6,16^{* *}$ \\
\hline
\end{tabular}

ns_- Não significativo; ${ }^{*}$ - significativo a $5 \%$ de probabilidade; ${ }^{* *}$ - significativo a $1 \%$ de probabilidade. As médias seguidas pela mesma letra não diferem estatisticamente entre si. Foi aplicado o Teste de Tukey ao nível de $5 \%$ de probabilidade.

Para avaliação do comprimento da parte aérea, o substrato contendo esterco de gado apresentou desempenho favorável para essa variável na cultura da alface (Tabela 4) aos 45 dias de transplantio. Este resultado vêm corroborar com Medeiros et al. (2001), os quais afirmam que o tipo de material orgânico influencia na produção final das plantas.

Cultura Agronômica, Ilha Solteira,v.26, n.4, p.520-529, 2017 
Do mesmo modo, Minami (2000) observaram que os substratos que têm na sua composição o vermicomposto e substratos de origem animal, apresentaram melhores propriedades físicas, químicas e físico-química para a produção de mudas de alface.

\section{CONCLUSÃO}

Para a avalição das plantas de alface quanto aos fatores de promoção de crescimento, aos 15 dias, o tratamento composto somente por terra preta teve efeito no número de folhas, comprimento da parte aérea e raiz. Entretanto para avaliação do peso da parte aérea e da raiz não houve efeito significativo.

Aos 30 dias de avaliação o substrato contendo cama de frango apresentou efeito significativo para o peso da parte aérea, contudo todos os outros parâmetros não apresentaram efeito significativo.

Em 45 dias de análise, após o transplantio, todos as variáveis analisadas apresentaram diferença significativa, o substrato contendo cama de frango teve efeito satisfatório para o número de folhas, peso da parte aérea e raiz e comprimento da raiz, para o comprimento da parte aérea, o substrato contendo esterco de gado apresentou efeito significativo.

Para todas as avaliações, ao final do ciclo da alface, recomenda-se o substrato orgânico para desenvolvimento da cultura, o que contenha terra preta + cama de frango.

\section{REFERÊNCIAS BIBLIOGRÁFICAS}

ABREU, M. F. Legislação de substratos para plantas. In: ENCONTRO NACIONAL SOBRE SUBSTRATO PARA PLANTAS, 5., 2006, Ilhéus. Anais... Ilhéus: Ceplac/Cepec, 2006. p.75-77.

ALVES, F. Q. G. Avaliação de diferentes substratos alternativos na qualidade de produção de mudas de alface. Cadernos de Agroecologia, Fortaleza, v.6, n.2, p.1-4,2011.

AYUSO, M., HERNANDEZ, T., GARCIA, C., PASCUAL, J. A. Stimulation of barley growth and nutrient absorption by humic substances originating from various organic materials. Bioresourceand Technology, Oxford, v. 57, n. 3, p.251-257, 1996.

BALDOTTO, L. E. B.; BALDOTTO M. A.; GIRO, V. B.; CANELLAS, L. P.; OLIVARES, F. L.; BRESSAN-SMITH, R. Desempenho do abacaxizeiro 'Vitória' em resposta à aplicação de ácidos húmicos durante a aclimatação. Revista Brasileira de Ciência do Solo, Viçosa, v. 33, n. 4, p.979-990, 2009.

BAUMGARTEN, A. Methods of chemical and physical evaluation of substrates for plants. In: ENCONTRO NACIONAL SOBRE SUBSTRATO PARA PLANTAS, 3., 2002, Campinas.Anais..., Campinas: IAC,2002. p.7-15. 
BOOMAN, J. Evolution of California substrates used in ornamental horticulture. In: ENCONTRO NACIONAL SOBRE SUBSTRATOPARA PLANTAS,1,Anais...Porto Alegre, Gênesis, 2000. p.23-42.

CARNEIRO, S. A. P.; GODOY, W. I.; FARINACIO, D.; WURTZIUS, V. Influencia de substratos alternativos e diferentes tipos de bandejas na cultura da alface. 2010. Disponível

em: http://www.prodirh.ufg.br/uploads/files/67/influ_ncia_de_substratos_alternativos_e_difere nt es_tipos_de_bandejas_na_cultura_da_alface_.pdf. Acesso em 15mar. 2014.

DINIZ, K. A.; GUIMARÃES, S. T. M. R.; LUZ, J. M. Q. Húmus como substrato para a produção de mudas de tomate, pimentão e alface. BioscienceJournal, Uberlândia, v. 22, n. 3, p.63-70, 2006.

FERREIRA, P. V. Estatística experimental aplicada à Agronomia. 3. ed. Maceió: EDUFAL, 2000. 422 p.

FILGUEIRA, F. A. R. Novo manual de olericultura: Agrotecnologia moderna na produção e comercialização de hortaliças. Viçosa: UFV, 2003. p. 402.

FONTENO, W. C. Substrates in horticulture. Acta Horticulture,Florence, v. 1, n.342, p.93$122,1993$.

GRUSZYNSKI, C. Resíduo agro-industrial "Casca de Tungue" como componente de substrato para plantas.2002. 92 f. Dissertação(Mestrado em Fitotecnia) - Programa de Pós-gradução, Universidade Federal do Rio Grande do Sul, Porto Alegre, 2002.

HARTMANN, H. T.; KESTER, D. E.; DAVIES JÙNIOR, F. T. Plant propagation: principles and practices. 5. ed. EnglewoodCliffs: Prentice Hall, 1990. 642 p.

KÄMPF, A. N. O estado da arte na pesquisa sobre substrato para plantas. In: ENCONTRO NACIONAL SOBRE SUBSTRATO PARA PLANTAS, 5., 2006, Ilhéus.Anais... Ilhéus: Ceplac/Cepec, 2006. p. 93-96.

LUZ, J. M. Q.; PAUlA, E. C.; GUIMARÃES, T. G. Produção de mudas de alface, tomateiro e couve-flor em diferentes substratos comerciais. Horticultura Brasileira, Brasília, v.18,supl.,p.579-581, 2000.

MEDEIROS, L.A.M. MANFRON, P.A.; MEDEIROS, S.L.P.; BONNECARRÉRE, R.A.G. Crescimento e desenvolvimento da alface (Lactuta sativa L.) conduzida em estufa plástica com fertirrigação em substratos. Ciência Rural, Santa Maria, v.31, n. 2, p.199-204, 2001.

MINAMI, K. Adubação em subtrato. In: KÄMPF, A. N., FERMINO, M. H. Substratos para plantas: a base da produção vegetal em recepientes. Porto Alegre: Gênesis, 2000. cap. 1, p.147-152.

MIRANDA, S. C; RIBEIRO, R. L. D.; RICCI, M. S. F.; ALMEIDA, D. L. Avaliação de substratos alternativos para a produção de mudas de alface em bandejas.Agrobiologia, Seropédica, v.1, n. 24, p.1-6, 1998.

Cultura Agronômica, Ilha Solteira,v.26, n.4, p.520-529, 2017 
NADAL, R.; GUIMARÃES, D. R.; BIASI, J.; PINHEIRO, S.L.G.; CARDOSO, V. T. M. Olericultura em Santa Catarina: aspectos técnicos e econômica. Florianópolis: EMPASC, 1986. 187p.

PIO, R.; GONTIJO, T.C.A.; CARRIJO, E.P.; RAMOS, J.D.; TOLEDO, M.; VISIOLI, E.L.; TOMASETTO, F. Efeito de diferentes substratos no crescimento de mudas de nespereira. Revista Brasileira Agrociência, Pelotas, v.10, n. 3, p.309-312, 2004.

RESENDE, G. M.; YURI, J. E.; MOTA, J. H.; SOUZA, R. J.; FREITAS, S. A. C.; RODRIGUES JÚNIOR, J. C. Efeitos de tipos de bandejas e idade de transplantio de mudas sobre o desenvolvimento e produtividade da alface americana. Horticultura Brasileira, Brasília, v. 21, n. 3, p.558-563, 2003.

RÖBER, R. Substratos hortícolas: possibilidades e limites de sua composição e uso; exemplos da pesquisa, da indústria e do consumo. In: ENCONTRO NACIONAL SOBRE SUBSTRATOPARA PLANTAS, 1. Anais ...Porto Alegre:Gênesis,2000. p.209 215.

SIlva, A, C.; CANEllaS, L. P.; OlivareS, F. L.; DOBBS, L. B.; AGUIAR, N. O.; FRADE, D. A. R.; REZENDE, C. E.; PERES, L. E. P. Promoção do crescimento radicular de plântulas de tomateiro por substâncias húmicas isoladas de turfeiras. Revista Brasileira de Ciência do Solo, Viçosa, v. 35, n.5, p.1609-1617, 2011.

SILVEIRA, E.B.; RODRIGUES, V.J.L.B.; GOMES, A.M.A.; MARIANO, R.L.R.; MESQUITA, J.C.P. Pó de coco como substrato para produção de mudas de tomateiro. Horticultura brasileira, Brasília, v.20, n.2, p.211-216, 2002.

SETUBAL, J. W.; C.; AFONSO NETO, F. Efeito de substratos alternativos e tipos de bandejas na produção de mudas de pimentão. Horticultura Brasileira, Brasília, v. 18, supl., p.593-594, 2000.

SCHMITZ, J. A. K.; SOUZA, P. V. D.; KÄMPF, A.N. Propriedades químicas e físicas de substratos de origem mineral e orgânica para o cultivo de mudas em recipientes. Ciência Rural, Santa Maria, v.32, n.6, p.937-944, 2002. 